\title{
A fast approach to determine a fed batch feeding profile for recombinant Pichia pastoris strains
}

\author{
Christian Dietzsch, Oliver Spadiut and Christoph Herwig ${ }^{*}$
}

\begin{abstract}
Background: The microorganism Pichia pastoris is a commonly used microbial host for the expression of recombinant proteins in biotechnology and biopharmaceutical industry. To speed up process development, a fast methodology to determine strain characteristic parameters, which are needed to subsequently set up fed batch feeding profiles, is required.

Results: Here, we show the general applicability of a novel approach to quantify a certain minimal set of bioprocess-relevant parameters, i.e. the adaptation time of the culture to methanol, the specific substrate uptake rate during the adaptation phase and the maximum specific substrate uptake rate, based on fast and easy-to-do batch cultivations with repeated methanol pulses in a batch culture. A detailed analysis of the adaptation of different $P$. pastoris strains to methanol was conducted and revealed that each strain showed very different characteristics during adaptation, illustrating the need of individual screenings for an optimal parameter definition during this phase. Based on the results obtained in batch cultivations, dynamic feeding profiles based on the specific substrate uptake rate were employed for different $P$. pastoris strains. In these experiments the maximum specific substrate uptake rate, which had been defined in batch experiments, also represented the upper limit of methanol uptake, underlining the validity of the determined process-relevant parameters and the overall experimental strategy.

Conclusion: In this study, we show that a fast approach to determine a minimal set of strain characteristic parameters based on easy-to-do batch cultivations with methanol pulses is generally applicable for different $P$. pastoris strains and that dynamic fed batch strategies can be designed on the specific substrate uptake rate without running the risk of methanol accumulation.
\end{abstract}

Keywords: Pichia pastoris, strain characterization, specific substrate uptake rate, batch cultivation, methanol pulse, dynamic feeding profile

\section{Background}

Advances in molecular biology, cloning techniques and strain improvement allowed an increasing use of recombinant organisms for the industrial production of a variety of substances like organic acids, antibiotics, enzymes and amino acids. In this context the methylotrophic yeast Pichia pastoris is one of the most important host organisms for the expression of recombinant proteins. To meet industrial demands, a fast and easy-to-do characterization of recombinant Pichia strains to extract bioprocess-relevant strain characteristic parameters for the

\footnotetext{
* Correspondence: christoph.herwig@tuwien.ac.at

Vienna University of Technology, Institute of Chemical Engineering, Research Area Biochemical Engineering, Vienna, Austria
}

subsequent set-up of production processes is essential to speed up process development. Normally, this strain characterization procedure is done by time-consuming experiments, which require complex and costly equipment, like continuous cultures $[1,2]$ or several, consecutive fed batch cultivations, operated at different conditions $[3,4]$. Parameters, which have to be extracted out of these experiments, describe the best operating conditions for each strain as well as the optimal condition for the adaptation of the culture from the growth substrate (e.g. glucose or glycerol) to the inducer methanol. To date, different strategies are employed regarding the adaptation of Pichia to methanol; two prominent examples are: 1) after a fed batch on glycerol or glucose a certain low concentration or flow of methanol is

\section{Biomed Central}


applied to the culture which is then increased to a predefined maximum and constantly maintained throughout the whole cultivation time [5,6], and 2) the glycerol flow in the reactor is decreased following a linear function during a concomitant addition of methanol, a period which is called transition phase, to slowly adapt the culture to methanol [7-10]. These methods are often based on specific experiences with a certain strain, but are nevertheless often used as a general approach for different Pichia strains in following studies, without taking into account the specific requirements of the single strains during adaptation.

After adaptation of the culture to methanol, different feeding strategies can be employed for recombinant protein production with $P$. pastoris. Besides the two common strategies of either using a feed forward regime or a controlled specific growth rate $(\mu)[6,7,9-14]$, a few studies have also described the importance of the specific substrate uptake rate $\left(\mathrm{q}_{\mathrm{s}}\right)$ on recombinant protein production $[15,16]$. A direct correlation between $\mathrm{q}_{\mathrm{s}}$ and the specific productivity $\left(\mathrm{q}_{\mathrm{p}}\right)$ was shown $[15,16]$, and it was clearly stated, that $\mathrm{q}_{\mathrm{s}}$ was the most important induction parameter in these experiments [17]. Based on those findings and motivated by problems which occur, when more traditional feeding strategies are applied (e.g. possible accumulation of methanol caused by changing cell capacities during cultivation or the need of expensive monitoring equipment to allow $\mu$-controlled feeding $[9,14])$, we have focused our research on the specific substrate uptake rate $\left(\mathrm{q}_{\mathrm{s}}\right)$ and have recently shown optimization potential using dynamic feeding profiles based on this parameter [18].

In our previous study we also developed a fast approach based on batch experiments with methanol pulses to extract a minimal set of strain characteristic parameters (i.e. $\Delta$ time $_{\text {adapt }}$ - time for adaptation, $\mathrm{q}_{\mathrm{s} \text { adapt }}$ - specific substrate uptake rate during adaptation, $\mathrm{q}_{\mathrm{s} \text { max }}$ - maximum specific substrate uptake rate), which are required to set up a subsequent feeding regime based on $\mathrm{q}_{\mathrm{s}}$. However, our previous study dealt with the development and the application of this approach for only one recombinant $P$. pastoris $\mathrm{Mut}^{\mathrm{S}}$ strain [18]. In the present work, we characterized various $P$. pastoris strains with different phenotypes $\left(\mathrm{Mut}^{\mathrm{s}}\right.$ and $\mathrm{Mut}^{+}$) expressing different target enzymes using the above mentioned strategy. We analyzed the required time for adaptation to methanol of each strain in detail and could reliably derive certain strain characteristic parameters from pulse experiments to fed batch cultivations. With the variety of used strains in this study, we demonstrate that this approach is generally applicable for different $P$. pastoris strains and is thus a valuable tool for fast process development, which is especially interesting in an industrial environment.

\section{Materials and methods}

The experiments conducted in the present study were performed according to our previous study [18], and are thus only described briefly here.

\section{Microorganisms and recombinant proteins}

Different $P$. pastoris strains with different phenotypes expressing different target enzymes were used in this study to prove the general applicability of our strategy. A list of the various strains is given in Table 1.

All recombinant genes used in this study were under the control of the AOX1 promoter. The expressed HRP gene coded for the isoenzyme HRP C1A. The strain KM71H PDI HRP concomitantly expressed HRP and the chaperone protein disulfide isomerase (PDI), which was under the control of a modified AOX1 promoter [19]. The strains KM71H, KM71H HRP, KM71H PDI HRP and CBS7435 HRP were gratefully provided by Prof. Anton Glieder (Graz University of Technology, Austria). The strain SMD1168H GalOX was constructed by Spadiut et al., as described elsewhere [20].

\section{Culture Media}

Precultures were performed in complex yeast nitrogen base media (YNBM), whereas batch and fed batch cultivations were done in defined basal salt media (BSM; [21]). The glucose feed was prepared with glucose (250 g. $\left.\mathrm{l}^{-1}\right)$, trace element solution PTM1 $\left(12 \mathrm{ml} \cdot \mathrm{l}^{-1}\right)$ and antifoam Struktol J650 $(0.3 \mathrm{ml} / \mathrm{l})$. The methanol feed was composed of methanol (300 $\left.\mathrm{g} \cdot \mathrm{l}^{-1}\right)$, PTM1 $\left(4 \mathrm{ml} \cdot \mathrm{l}^{-1}\right)$ and Struktol J650 $\left(0.3 \mathrm{ml} \cdot \mathrm{l}^{-1}\right)$. The induction period for HRP expression was carried out in the presence of $\delta$-Aminolevulinic acid ( $\delta$-ALA) in a final concentration of $1 \mathrm{mM}$. The concentration of the base $\mathrm{NH}_{4} \mathrm{OH}$ was determined by titration with $0.25 \mathrm{M}$ potassium hydrogen phthalate (KHP).

\section{Experimental Procedure \\ Preculture}

Frozen stocks $\left(-80^{\circ} \mathrm{C}\right)$ were precultivated in $100 \mathrm{ml}$ of YNBM in $1000 \mathrm{ml}$ shake flasks at $28^{\circ} \mathrm{C}$ and $230 \mathrm{rpm}$ for max. 24 hours.

Table 1 Different $\boldsymbol{P}$. pastoris strains used in this study

\begin{tabular}{cccc}
\hline Strain & phenotype & $\begin{array}{c}\text { expressed } \\
\text { enzyme }\end{array}$ & $\begin{array}{c}\text { in this study designated } \\
\text { as }\end{array}$ \\
\hline KM71H & Mut $^{S}$ & - & KM71H \\
KM71H & Mut $^{S}$ & HRP & KM71H HRP \\
KM71H & Mut $^{S}$ & PDI and HRP & KM71H PDI HRP \\
CBS7435 & Mut $^{S}$ & HRP & CBS7435 HRP \\
SMD1168H & Mut $^{+}$ & GalOX & SMD1168H GalOX \\
\hline
\end{tabular}




\section{Batch cultivation with methanol pulses}

Batch cultivations were carried out in a 51 working volume glass bioreactor (Infors, Switzerland) at $28^{\circ} \mathrm{C}$ and a fixed agitation speed of $1200 \mathrm{rpm}$. The culture was aerated with $1 \mathrm{vvm}$ dried air and off-gas was measured by using an infrared cell for $\mathrm{CO}_{2}$ and a paramagnetic cell for $\mathrm{O}_{2}$ concentration (Servomex, Switzerland). Process parameters were recorded and logged in a process information management system (PIMS; Lucullus, Biospectra, Switzerland). After the complete consumption of glucose, which was indicated by an increase of dissolved oxygen and a drop in off-gas activity, the first methanol pulse (adaptation pulse) with a final concentration of $0.5 \%(\mathrm{v} / \mathrm{v})$ was conducted with pure methanol (supplemented with PTM1, $12 \mathrm{ml} \cdot \mathrm{l}^{-1}$ of methanol). Following pulses were performed with $1 \%(\mathrm{v} / \mathrm{v})$ concentration of methanol. For all strains, several pulses were conducted after the adaptation pulse to generate consistent data for each strain. For each methanol-pulse, at least two samples were taken to determine the concentrations of substrate and product as well as dry cell weight and $\mathrm{OD}_{600}$ to calculate the specific substrate uptake rate $\mathrm{q}_{\mathrm{s}}$.

\section{Fed batch cultivations}

Fed batch cultivations were carried out in a 51 working volume glass bioreactor (Infors, Switzerland) in 2-fold concentrated BSM medium at $28^{\circ} \mathrm{C}$ and $1500 \mathrm{rpm}$. The culture was aerated with at least $1 \mathrm{vvm}$ to keep dissolved oxygen levels $>30 \%$. In case, air flow was limited, pure oxygen was added. The fed batch feed was measured and controlled using a gravimetrically based PID flow controller. At several time points during fed batch cultivations, samples were taken and analyzed for accumulated methanol, biomass concentration (dry cell weight and optical density $\mathrm{OD}_{600}$ ) and, if applicable, enzymatic activity. Based on the total biomass content, feeding rates were adjusted manually corresponding to the defined $\mathrm{q}_{\mathrm{s}}$ set point. All fed batches described in this study were conducted in the same way: after an adaptation period at $\mathrm{q}_{\mathrm{s}}$ of $0.5 \mathrm{mmol} \cdot \mathrm{g}^{-1} \cdot \mathrm{h}^{-1}$, a stepwise increase of $\mathrm{q}_{\mathrm{s}}$ up to $\mathrm{q}_{\mathrm{s} \text { max }}$ of the respective strain was carried out with step times of 24 hours.

\section{Analysis of growth- and expression-parameters}

Dry cell weight $(\mathrm{DCW}), \mathrm{OD}_{600}$, substrate concentrations as well as the catalytic activity of HRP were determined as described before [18]. However, in this study the ABTS solution for HRP activity measurements was prepared in $50 \mathrm{mM} \mathrm{KH}_{2} \mathrm{PO}_{4}$-buffer at $\mathrm{pH} 6.5$ and the calibration range was expanded to $2.0 \mathrm{U} \cdot \mathrm{ml}^{-1}$. Also GalOX activity was measured with an ABTS assay; i.e. a sample of diluted enzyme $(10 \mu \mathrm{l})$ was added to $990 \mu \mathrm{l}$ of assay buffer containing horseradish peroxidase (222 U) (Type VI-A, Sigma-Aldrich, P6782), ABTS (17.7 mg), $\mathrm{KH}_{2} \mathrm{PO}_{4^{-}}$ buffer (50 mM, pH 6.5) and D-galactose (300 mM). The absorbance change at $420 \mathrm{~nm}\left(\varepsilon_{420}=42.3 \mathrm{mM}^{-1} \cdot \mathrm{cm}^{-1}\right)$ was recorded at $30^{\circ} \mathrm{C}$ for 180 seconds. One Unit of GalOX activity was defined as the amount of enzyme necessary for the oxidation of $2 \mu \mathrm{mol}$ of ABTS per min, corresponding to the consumption of $1 \mu \mathrm{mol}$ of $\mathrm{O}_{2}$ per min. An additional post-translational activation of GalOX by adding $\mathrm{CuSO}_{4}$ to the samples in the presence of oxygen before activity measurements, as described elsewhere [20], was not executed.

\section{Specific rate calculations Batch cultivations}

To obtain the specific rates for substrate uptake and productivity, samples were taken at certain time points during the methanol pulses (i.e. beginning of pulse, maximum off-gas of pulse, end of pulse) and analyzed offline for biomass content, methanol concentration and, if applicable, enzymatic activity. Determined values at the beginning and the end of the respective pulse were used to calculate an average rate of the specific substrate uptake, which was corrected for stripping using Antoine's equation, and the specific productivity. Errors for specific rates were set to $10 \%$, according to our previous study [18]. Online calculated carbon dioxide evolution rate (CER) was divided by actual biomass concentrations to obtain the specific carbon dioxide production rate $\left(\mathrm{qCO}_{2}\right)$. In addition, a time derivative of the $\mathrm{qCO}_{2}$ signal (i.e. $\mathrm{qCO}_{2}{ }^{\prime}$ ) was calculated using a time window of 30 minutes ( 15 minutes before and 15 minutes after the actual time point).

\section{Fed batch cultures}

During different cultivation periods, representing defined $\mathrm{q}_{\mathrm{s}}$ set points, several samples were taken and $\mathrm{OD}_{600}$ measurements were used to calculate the actual total biomass content, which allowed adjustments of the methanol feed flow to the actual $\mathrm{q}_{\mathrm{s}}$ set point. Specific rates were calculated using DCW and the amount of consumed methanol, which was determined gravimetrically. Presented results correspond to an average value over the respective $\mathrm{q}_{\mathrm{s}}$ set point period. Again, errors for specific rates were set to $10 \%$.

\section{Results and Discussion}

\section{A fast approach to derive a minimal set of strain characteristic parameters relevant for bioprocess development}

Each $P$. pastoris strain was cultivated in an easy-to-do batch system with methanol pulses to obtain certain strain characteristic parameters during the adaptation period ( $\Delta$ time $_{\text {adapt }}$ - time for adaptation of the culture to methanol, $\mathrm{q}_{\mathrm{s} \text { adapt }}$ - specific substrate uptake rate during the adaptation pulse) and the maximum specific substrate uptake rate $\left(\mathrm{q}_{\mathrm{s} \max }\right)$. These parameters were 
extracted and consecutively transformed into a feeding profile for fed batch operations based on $\mathrm{q}_{\mathrm{s}}$.

\section{Adaptation of the culture to methanol}

After depletion of glucose in batch cultivation, a methanol adaptation pulse with a final concentration of $0.5 \%$ $(\mathrm{v} / \mathrm{v})$ was applied. The time required to develop a maximum in off-gas activity was used to define $\Delta$ time $_{\text {adapt }}$, according to our previous study [18], and is shown here as the specific carbon dioxide production rate $\left(\mathrm{qCO}_{2}\right.$; Figure 1).

The used strains showed very different metabolic characteristics during the adaptation to methanol. The shortest $\Delta$ time $_{\text {adapt }}$ of $3.5 \mathrm{~h}$ was detected for the $\mathrm{KM} 71 \mathrm{H}$ strain, which was a Mut ${ }^{\mathrm{S}}$ strain, not carrying a recombinant gene for heterologous protein expression. The other Mut $^{\mathrm{S}}$ strains KM71H HRP, KM71H PDI HRP and CBS7435 HRP (Figure 1B, C and 1D, respectively) showed 2-fold longer adaptation times compared to the KM71H strain (see also Table 2). These results clearly show that recombinant Pichia strains, which heterologously produce proteins upon the presence of the inducer methanol, carry an additional biological burden which significantly changes their metabolism and slows down their adaptation to methanol.

Surprisingly, the P. pastoris $\mathrm{Mut}^{+}$strain SMD1168H GalOX showed the longest adaptation time of $14 \mathrm{~h}$ (Figure $1 \mathrm{E}$ ). However, this maximum was just detected as a result of methanol depletion and thus Monod kinetics, rather than representing the real time point of full methanol adaptation. As shown in Figure 1, the $\mathrm{Mut}^{+}$ strain SMD1168H GalOX showed a very different metabolic behaviour with a flat slope for $\mathrm{qCO}_{2}$ compared to the $\mathrm{qCO}_{2}$ curves of the $\mathrm{Mut}^{\mathrm{S}}$ strains, which might be due to intracellular regulation and inhibition events, caused by produced $\mathrm{H}_{2} \mathrm{O}_{2}$ and the absence of sufficient catalases in the cells. Regulation events like this have been described in various systems before [22-24]. Thus, the determined $\Delta$ time $_{\text {adapt }}$ of $14 \mathrm{~h}$ for the $\mathrm{Mut}^{+}$strain is questionable and the cells had probably been adapted to methanol before.

Consequently, the usefulness of the strain characteristic parameter $\Delta$ time $_{\text {adapt }}$, especially with regard to the Mut $^{+}$strain SMD1168H GalOX, was checked by introducing a time derivative of the $\mathrm{qCO}_{2}$ signal $\left(\mathrm{qCO}_{2}{ }^{\prime}\right)$. Since $\mathrm{qCO}_{2}$ and the specific growth rate $\mu$ are linearly related, the maximum of $\mathrm{qCO}_{2}$ ' represents the time point of adaptation of the culture to the new substrate methanol. At the maximum $\mathrm{qCO}_{2}$ ' the cells should be already fit for further assimilation to methanol, and thus this point represents a good starting point for consecutive fed batch cultivations without running the risk of methanol accumulation. A good example for this is shown in Figure 1A for the strain $\mathrm{KM} 71 \mathrm{H}$, where a rising slope is shown with a single $\mathrm{qCO}_{2}$ ' maximum after
$2.1 \mathrm{~h}$. However, the other Mut ${ }^{\mathrm{S}}$ strains tested (KM71H HRP, KM71H PDI HRP and CBS7435 HRP) were characterized by a more bumpy $\mathrm{qCO}_{2}$ curve, resulting in a $\mathrm{qCO}_{2}$ ' signal with several shoulders (Figure $1 \mathrm{~B}, \mathrm{C}$ and $1 \mathrm{D}$, respectively). Apparently, the adaptation of these strains to methanol did not happen as straight-forward as for the strain $\mathrm{KM} 71 \mathrm{H}$, but with local minima and maxima of the metabolic capacity probably caused by regulatory events upon an excess of methanol. For the $\mathrm{Mut}^{+}$strain SMD1168H GalOX the specific carbon dioxide production was rather low compared to the Mut strains. The maximum in $\mathrm{qCO}_{2}$ ' was determined already after $2.7 \mathrm{~h}$, which was by far sooner than the observed $\Delta$ time adapt of $14 \mathrm{~h}$. The quite constant $\mathrm{qCO}_{2}{ }^{\prime}$ signal over time (Figure 1E), further supports the fact that the cell capacity was already adapted to its maximum after this short time of $2.7 \mathrm{~h}$ and that the cells had been fully adapted to methanol much sooner than the $\Delta$ time $_{\text {adapt }}$ of $14 \mathrm{~h}$.

In general, the more detailed analysis of the different strains in their adaptation to methanol revealed three different patterns in the $\mathrm{qCO}_{2}$ ' signal: 1 ) with a single maximum, 2) with several shoulders and 3) a quite constant signal over time. This underlines the necessity for individual analyses of different strains in order to quantitatively characterize them during the adaptation phase in the presence of methanol excess. Of course, the observed maximum in off-gas activity is dependent on the affinity of the cells to the substrate methanol. The maximum in $\mathrm{qCO}_{2}$ could also be reached in terms of substrate limitation and a consequent drop in the $\mathrm{qCO}_{2}$ signal due to Monod kinetics rather than by the maximum metabolic adaptation to methanol, which in this study can clearly be seen for the $\mathrm{Mut}^{+}$strain SMD1186H GalOX (Figure 1E). However, for all strains tested in this study, maximum values of $\mathrm{qCO}_{2}$ ' were reached before the maximum off-gas activity (Figure 1 and Table 2), demonstrating that the applied concentration of methanol in the adaptation pulse was high enough to guarantee that the maximum $\mathrm{qCO}_{2}$ ' was reached independent of Monod kinetic effects. The validity of $\mathrm{qCO}_{2}$ ' as a reliable signal to detect the adaptation of the culture to methanol is further underlined when analyzing the respiratory quotient (RQ) during the adaptation pulse, which is exemplarily shown for the strain $\mathrm{KM} 71 \mathrm{H}$ in Figure 2. During the adaptation pulse, RQ fluctuates with local minima and maxima until the signal becomes rather constant indicating the adaptation of the culture to methanol, which actually coincides with the maximum of $\mathrm{qCO}_{2}$ '. Bespoken fluctuations of $\mathrm{RQ}$ at the beginning of the adaptation pulse represent the differences in catabolic and anabolic activity of the adapting cells. Similar effects have been observed for Saccharomyces cerevisiae $[22,25,26]$. During the 

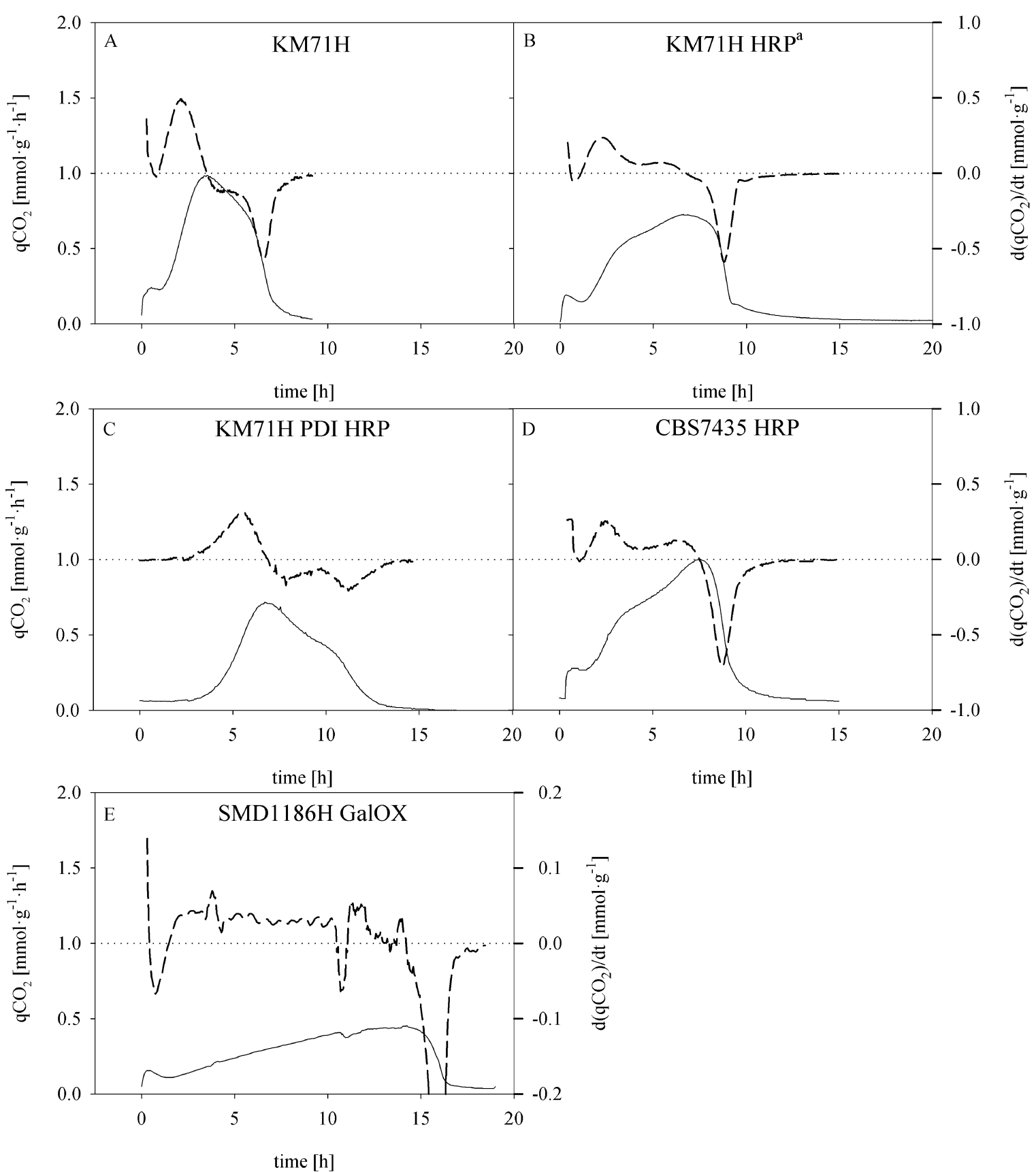

time $[\mathrm{h}]$

Figure 1 Adaptation pulses with $\mathbf{0 . 5 \%}(\mathrm{v} / \mathrm{v})$ methanol after glucose depletion for different $\boldsymbol{P}$. pastoris strains. Straight line, specific carbon dioxide production rate $\mathrm{qCO}_{2}$; dashed line, time-derivative of the specific carbon dioxide production rate $\mathrm{q} \mathrm{CO}_{2}^{\prime}\left(\mathrm{d}\left(\mathrm{qCO}_{2}\right) / \mathrm{dt}\right) ; \mathrm{A}, \mathrm{KM} 71 \mathrm{H}$; B, KM71H HRP'; C, KM71H PDI HRP; D, CBS7435 HRP; E, SMD1168H GalOX. adata taken from [18]

following pulses, RQ shows a rather constant signal indicating that the cells had already been adapted to the new substrate. These findings validate the parameter $\mathrm{qCO}_{2}$ ' as a reliable indicator for methanol adaptation.

However, despite the advantage of describing the time point of adaptation of the culture to methanol more accurately, the use of $\mathrm{qCO}_{2}{ }^{\prime}$ as a parameter to determine the starting point of the following fed batch could be risky because of the described fluctuations in $\mathrm{qCO}_{2}$ (Figure 1). On the other hand, the maximum off-gas activity $\left(\Delta\right.$ time $\left._{\text {adapt }}\right)$ is a parameter which safely describes methanol adaptation. Another advantage of using $\Delta$ time $_{\text {adapt }}$ instead of $\mathrm{qCO}_{2}$ ' is the fact that due to no significant biomass increase during the adaptation 
Table 2 Batch experiments with methanol pulses to determine strain specific parameters of different $\boldsymbol{P}$. pastoris strains.

\begin{tabular}{|c|c|c|c|c|c|}
\hline & KM71H & KM71H HRP & KM71H PDI HRP & CBS7435 HRP & SMD1168H GalOX \\
\hline$\Delta$ time $_{\text {adapt Batch }}[\mathrm{h}]$ & 3.5 & 7 & 7 & 7.5 & 14 \\
\hline $\max . \mathrm{qCO}_{2}^{\prime}[\mathrm{h}]$ & 2.1 & 2.3 & 5.7 & 2.5 & 2.7 \\
\hline $\begin{array}{c}\mathrm{q}_{\mathrm{s} \text { adapt }} \\
{\left[\mathrm{mmol} \cdot \mathrm{g}^{-1} \cdot \mathrm{h}^{-1}\right]}\end{array}$ & $0.96 \pm 0.10$ & $0.80 \pm 0.08$ & $0.56 \pm 0.06$ & $0.77 \pm 0.08$ & $0.48 \pm 0.05$ \\
\hline $\begin{array}{c}\mathrm{q}_{\mathrm{s} \max } \\
{\left[\mathrm{mmol} \cdot \mathrm{g}^{-1} \cdot \mathrm{h}^{-1}\right]}\end{array}$ & $1.94 \pm 0.19$ & $2.00 \pm 0.20$ & $1.08 \pm 0.10$ & $1.54 \pm 0.15$ & $2.62 \pm 0.26$ \\
\hline $\begin{array}{c}q_{p} \max ^{b} \\
{\left[U \cdot g^{-1} \cdot h^{-1}\right]}\end{array}$ & - & $2.5 \pm 0.25$ & $6.3 \pm 0.63$ & $4.25 \pm 0.43$ & $200.8 \pm 20.1$ \\
\hline
\end{tabular}

a data taken from [18]

${ }^{b}$ representing the maximum value determined out of all pulses

pulses, the carbon dioxide evolution rate (CER), which can easily be derived in online mode, can be used to determine $\Delta$ time $_{\text {adapt }}$, as also shown in our previous study [18], and thus describes a valuable online tool for process monitoring and control. Consequently, we stuck to $\Delta$ time $_{\text {adapt }}$ as a minimum and safe parameter for complete methanol adaptation, as we have done previously [18], while the maximum of $\mathrm{qCO}_{2}$ ' should be regarded as a possible minimum prerequisite to start the fed batch feed.
Determination of the specific substrate uptake rates $\left(q_{s}\right.$ adapt and $\left.q_{s \text { max }}\right)$ using batch cultivations with repeated methanol pulses

The frequent determination of biomass and methanol concentrations allowed specific rate calculations for methanol uptake $\left(\mathrm{q}_{\mathrm{s}}\right)$ during the methanol pulses. Adaptation pulses of $0.5 \%(\mathrm{v} / \mathrm{v})$ methanol were used to determine the parameter $\mathrm{q}_{\mathrm{s} \text { adapt }}$ (specific substrate uptake rate during the adaptation pulse) for each strain (Table 2 ). The knowledge of $\mathrm{q}_{\mathrm{s} \text { adapt }}$ allows the operator to

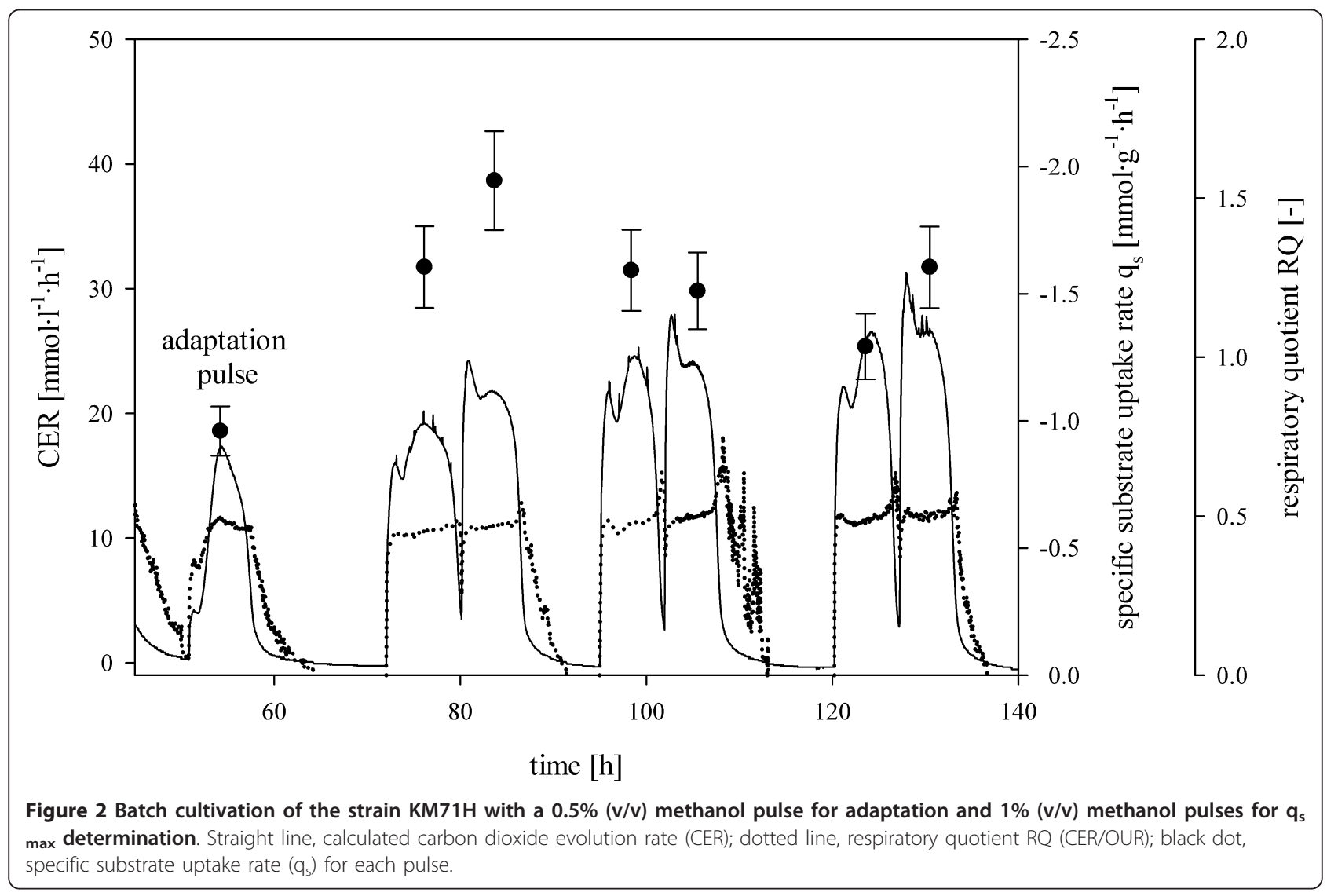


adjust a specific, optimal flow of methanol during the adaptation for each single strain, thus preventing methanol accumulation.

After the methanol of the adaptation pulse was depleted, several pulses with $1 \%(\mathrm{v} / \mathrm{v})$ methanol were conducted to determine the maximum specific substrate uptake rate $\left(\mathrm{q}_{\mathrm{s} \text { max }}\right)$ for each $P$. pastoris strain. In Figure 2 , this strategy is exemplarily shown for the $\mathrm{Mut}^{\mathrm{S}}$ strain $\mathrm{KM} 71 \mathrm{H}$, for which the specific substrate uptake rate was calculated with $0.96 \pm 0.09 \mathrm{mmol} \cdot \mathrm{g}^{-1} \cdot \mathrm{h}^{-1}$ in the adaptation period $\left(\mathrm{q}_{\mathrm{s}}\right.$ adapt $)$ and with $1.94 \pm 0.19$ $\mathrm{mmol} \cdot \mathrm{g}^{-1} \cdot \mathrm{h}^{-1}$ as a maximum during pulses (Figure 2 and Table 2). All P. pastoris strains were characterized with the above mentioned strategy and results are summarized in Table 2. Very different values for the single strain characteristic parameters of the different $P$. pastoris strains were determined and it becomes evident, that $P$. pastoris strains require specific conditions for an optimal adaptation to methanol and that the maximum levels of methanol uptake differ significantly between the single strains.

Summing up, our results underline the importance of analyzing different $P$. pastoris strains in more detail during methanol adaptation and regarding the maximum substrate uptake rate. By a more detailed analysis of each strain, which can be done in a fast way by the strategy described here, the bioprocess-relevant strain characteristic parameters $\Delta$ time $_{\text {adapt }}, \mathrm{q}_{\mathrm{s} \text { adapt }}$ and $\mathrm{q}_{\mathrm{s} \max }$ can be easily extracted and used for setting up a consecutive fed batch experiment based on $\mathrm{q}_{\mathrm{s}}$. Additionally, the more detailed individual analysis of each strain during the adaptation phase delivers important information for an early process development.

\section{Fed batch design based on batch cultivations with methanol pulses}

After characterization experiments in batch cultivations, fed batch experiments using $\mathrm{q}_{\mathrm{s}}$ based feeding profiles were carried out, according to our previous study [18]. Besides proving the general applicability of this feeding strategy on different $P$. pastoris strains, we wanted to check for parameter consistency, i.e. whether $\mathrm{q}_{\mathrm{s} \max }$, which had been determined in batch experiments before, could be reached in fed batch cultivations without observable methanol accumulation.

After a batch phase on glucose as substrate (volume $1.5 \mathrm{l}$ ), an exponential fed batch cultivation with glucose yielded in biomass concentrations of up to $70 \mathrm{~g} / \mathrm{l}$ in a final volume of $2.5 \mathrm{l}$. As soon as glucose was depleted, a sample was taken to determine the current biomass concentration by measuring the $\mathrm{OD}_{600}$ and the $\mathrm{DCW}$. Afterwards, all cultures were induced with a flow corresponding to a $\mathrm{q}_{\mathrm{s}}$ below $\mathrm{q}_{\mathrm{s} \text { adapt }}$ to guarantee a certain safety margin. The observed adaptation times during the fed batch cultivations for all strains are summarized in Table 3. All the Mut ${ }^{\mathrm{S}}$ strains were characterized by slightly longer adaptation times in fed-batches compared to the batch cultivations, which might be due to the mode of providing methanol, i.e. in batch experiments methanol was pulsed into the reactor, resulting in a temporal excess of methanol, whereas in fed batch cultivations methanol was slowly fed into the bioreactor according to the actual biomass content, which is why it took the cells longer to fully adapt to the new substrate methanol.

However, the $\mathrm{Mut}^{+}$strain SMD1168H GalOX showed a completely different behaviour: the adaptation time in the fed batch was much shorter than the one observed in the batch experiment, which might be due to the fact that the sudden excess of methanol in the batch-pulse experiment resulted in inhibition events caused by produced $\mathrm{H}_{2} \mathrm{O}_{2}$ and thus $\Delta$ time $_{\text {adapt }}$, which had been determined in the batch experiment, did not really describe the time point of adaptation of the culture to methanol, but rather $\mathrm{qCO}_{2}$ ' (vide supra).

However, as soon as the maximum in off-gas activity was reached in the fed batch cultivations, the feed was increased to $1.0 \mathrm{mmol} \cdot \mathrm{g}^{-1} \cdot \mathrm{h}^{-1}$ and then stepwise $(0.5$ $\left.\mathrm{mmol} \cdot \mathrm{g}^{-1} \cdot \mathrm{h}^{-1} / \mathrm{step}\right)$ every 24 hours up to $\mathrm{q}_{\mathrm{s} \text { max }}$. Since $\mathrm{q}_{\mathrm{s}}$ max for the strain KM71H HRP PDI had been determined with just $1.08 \mathrm{mmol} \cdot \mathrm{g}^{-1} \cdot \mathrm{h}^{-1}$, smaller increases of $0.25 \mathrm{mmol} \cdot \mathrm{g}^{-1} \cdot \mathrm{h}^{-1}$ in the $\mathrm{q}_{\mathrm{s}}$ steps were performed. This strategy, describing a stepwise increase of $\mathrm{q}_{\mathrm{s}}$ to $\mathrm{q}_{\mathrm{s} \max }$, was chosen to allow the detection of possible

Table 3 Results of dynamic fed batch cultivations of different $\boldsymbol{P}$. pastoris strains based on $\mathrm{q}_{\mathrm{s}}$.

\begin{tabular}{|c|c|c|c|c|c|}
\hline & KM71H & KM71H HRP ${ }^{a}$ & KM71H PDI HRP & CBS7435 HRP & SMD1168H GalOx \\
\hline$\Delta$ time $_{\text {adapt Fedbatch }}[\mathrm{h}]$ & 5.5 & 9.7 & 10.4 & 9.2 & 5.3 \\
\hline $\begin{array}{c}\mathrm{q}_{\mathrm{s} \text { max }} \text { determined in batch experiments } \\
{\left[\mathrm{mmol} \cdot \mathrm{g}^{-1} \cdot \mathrm{h}^{-1}\right]}\end{array}$ & $1.94 \pm 0.19$ & $2.00 \pm 0.21$ & $1.08 \pm 0.10$ & $1.54 \pm 0.15$ & $2.62 \pm 0.26$ \\
\hline $\begin{array}{l}\mathrm{q}_{\mathrm{s}} \text { reached without methanol accumulation } \\
\qquad\left[\mathrm{mmol} \cdot \mathrm{g}^{-1} \cdot \mathrm{h}^{-1}\right]\end{array}$ & $1.79 \pm 0.18$ & $1.92 \pm 0.19$ & $1.22 \pm 0.12$ & $1.64 \pm 0.16$ & $2.44 \pm 0.24$ \\
\hline $\begin{array}{c}q_{p} \max ^{b} \\
{\left[U \cdot g^{-1} \cdot h^{-1}\right]}\end{array}$ & - & $11.0 \pm 1.10$ & $7.09 \pm 0.10$ & $6.48 \pm 0.65$ & $139 \pm 13.9$ \\
\hline
\end{tabular}

\footnotetext{
a data taken from [18]

${ }^{b}$ representing the maximum value determined out of all $q_{s}$ periods
} 
dependencies between $\mathrm{q}_{\mathrm{s}}$ and $\mathrm{q}_{\mathrm{p}}$. At several time points during each step, samples were taken and, based on the apparent biomass content (estimated by $\mathrm{OD}_{600}$ measurements) feeding rates were adjusted manually corresponding to the defined $\mathrm{q}_{\mathrm{s}}$ set point. Since these regular adjustments of $\mathrm{q}_{\mathrm{s}}$ to the actual biomass content were performed, the feeding profile actually represented an accelerated exponential feeding profile, which has proven to result in higher specific productivities compared to other feeding profiles tested [18].

In Figure 3, this fed batch strategy, which was applied for all $P$. pastoris strains in this study, is exemplarily shown for the $\mathrm{Mut}^{\mathrm{s}}$ strain $\mathrm{KM} 71 \mathrm{H}$ and the $\mathrm{Mut}^{+}$strain SMD1186H GalOX. The $\mathrm{q}_{\mathrm{s}}$ set points were increased stepwise to a value of $2.00 \mathrm{mmol} \cdot \mathrm{g}^{-1} \cdot \mathrm{h}^{-1}$ for the $\mathrm{KM} 71 \mathrm{H}$ strain, and, as shown in Figure 3A, methanol accumulation was only observed when the feeding rate exceeded values above the respective $\mathrm{q}_{\mathrm{s}} \max$ of $1.94 \pm 0.19$ $\mathrm{mmol} \cdot \mathrm{g}^{-1} \cdot \mathrm{h}^{-1}$. When we stopped feeding after $\sim 70 \mathrm{~h}$, the accumulated methanol was consumed immediately.

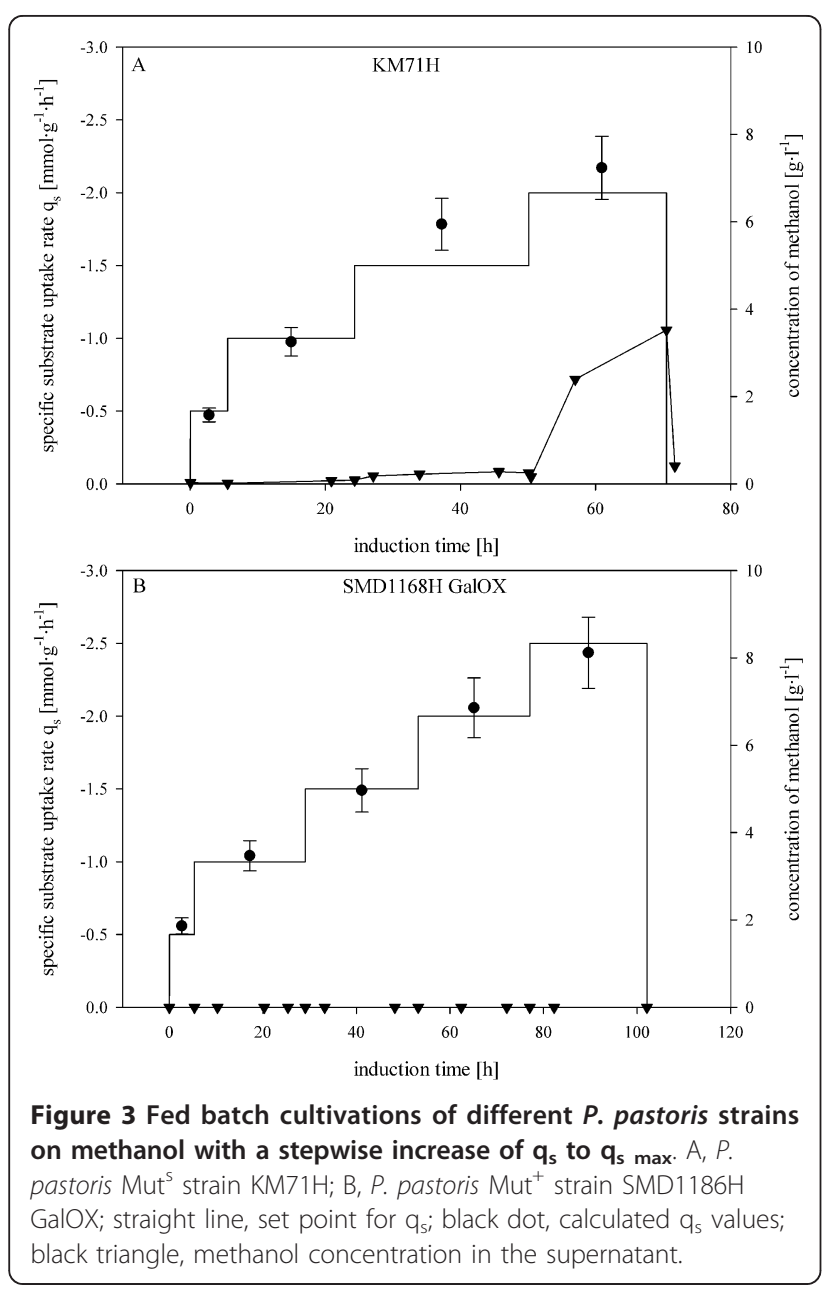

For the strain SMD1168H GalOX, the $\mathrm{q}_{\mathrm{s}}$ set point was stepwise increased to $2.5 \mathrm{mmol} \cdot \mathrm{g}^{-1} \cdot \mathrm{h}^{-1}\left(\mathrm{q}_{\mathrm{s} \text { max }}=2.62\right.$ $\mathrm{mmol} \cdot \mathrm{g}^{-1} \cdot \mathrm{h}^{-1}$ ) and no methanol accumulation was detected when these $\mathrm{q}_{\mathrm{s}}$ steps were conducted (Figure 3B). The same dynamic feeding strategy was applied to the other $P$. pastoris strains and all essential results are summarized in Table 3.

As shown in Table 3, values for $\mathrm{q}_{\mathrm{s} \text { max }}$, which had been determined in batch pulsing experiments before, were reached in fed batch experiments without methanol accumulation. However, when $\mathrm{q}_{\mathrm{s}}$ set points were further increased, methanol accumulation was observed. This proves that the values for $\mathrm{q}_{\mathrm{s} \text { max }}$ from batch experiments can be found again in consecutive fed batch experiments for different $P$. pastoris strains and thus shows the great potential of this approach: by determining $\mathrm{q}_{\mathrm{s} \text { max }}$ in fast and easy-to-do batch experiments, the operator does not run the risk of overfeeding methanol in consecutive fed batch cultivations. However, we recommend a maximum feed flow below $\mathrm{q}_{\mathrm{s} \text { max }}$ to guarantee a certain safety margin.

Regarding the productivity, for all the strains, except for SMD1168H GalOX, same or even higher specific productivities were obtained in fed batch cultures compared to the batch experiments, signifying that volumetric productivities were higher in fed batch cultivations compared to batch experiments (Table 2 and Table 3). This shows that our approach employing dynamic feeding profiles [18] can be successfully applied on different $P$. pastoris strains. The lower $\mathrm{q}_{\mathrm{p} \max }$ of the strain SMD1168H GalOX in fed batch cultivation probably resulted from copper-limitation [20], but was not investigated any further, since it was not goal of this study to optimize the production of recombinant enzymes of the single $P$. pastoris strains.

Summing up, in this study we show the general applicability of a fast approach to determine certain strain characteristic parameters, which were extracted out of batch experiments and were verified in subsequent fed batch cultures of different $P$. pastoris strains, making this approach a valuable tool for fast bioprocess development.

\section{Conclusions}

In the present study we prove that the fast approach to determine bioprocess-relevant strain characteristic parameters and the novel dynamic feeding strategy based on $\mathrm{q}_{\mathrm{s}}$, which we have described recently for one recombinant $P$. pastoris strain [18], are applicable for a variety of $P$. pastoris strains with different phenotypes producing different recombinant proteins. This underlines the great potential of this strategy as a fast and simple tool to quantify a minimal set of parameters needed to set 
up consecutive fed batch regimes, which is particularly important for industry, where a fast process development is essential.

Our strategy describes:

1. a batch experiment with

- a $0.5 \%(\mathrm{v} / \mathrm{v})$ methanol adaptation pulse to determine $\Delta$ time adapt $_{\text {and }} \mathrm{q}_{\mathrm{s} \text { adapt }}$

- at least 4 consecutive $1.0 \%(\mathrm{v} / \mathrm{v})$ methanol pulses to determine $\mathrm{q}_{\mathrm{s} \max }$

2. a dynamic fed batch feeding strategy based on $\mathrm{q}_{\mathrm{s}}$, where after the adaptation of the culture to methanol (described by a maximum in off-gas activity), $\mathrm{q}_{\mathrm{s}}$ set points can be increased to $\mathrm{q}_{\mathrm{s} \max }$ without observable methanol accumulation

We further show that a detailed analysis of the adaptation to methanol reveals a variability of adaptation characteristics of the different strains, highlighting that an individual analysis of potentially new strains in this respect is required to allow quantitative strain characterization and to derive parameters necessary for a consecutive fed batch set-up. The parameter $\Delta$ time $_{\text {adapt }}$ safely describes the transition condition during methanol adaptation. Since also the carbon dioxide evolution rate (CER), as well as the oxygen uptake rate (OUR), can be used to determine $\Delta$ time $_{\text {adapt }}$, it further describes an online available data source allowing real-time monitoring and controlling of bioprocesses, which is essential under the aspect of Process Analytical Technology (PAT).

In this study we show that easy-to-do batch experiments with methanol pulses delivered valid and safe strain characteristic parameters which were consistent and precise enough to set up fed batch feeding profiles based on the specific substrate uptake rate. Our strategy is faster than the usually used continuous cultures or consecutive fed batch cultivations, and therefore allows faster process development. Besides, the strategy described here can be carried out using standard equipment without the need of cost-intensive tools; only a standard bioreactor connected to an off-gas analysis system and an HPLC or GC to determine methanol concentrations are required to carry out the experiments.

\section{List of Abbreviations}

$\Delta$ time $_{\text {adapt }}$ : mtime for adaptation of the culture to the new substrate (methanol) $[\mathrm{h}]$; $\mu$ : specific growth rate $\left[\mathrm{h}^{-1}\right]$; ABTS: $2,2^{\prime}$ azino bis 3ethylbenzthiazoline-6-sulphonic acid; CER- carbon dioxide evolution rate $\left[\left.\mathrm{mmol} \cdot\right|^{-1} \cdot \mathrm{h}^{-1}\right]$; $\mathrm{d}\left(\mathrm{qCO}_{2}\right) / \mathrm{dt}$ : derivative of $\mathrm{qCO}_{2}$; DCW: dry cell weight; $\mathrm{HPLC}$ high performance liquid chromatography; HRP: horseradish peroxidise; GalOX: galactose 6-oxidase; Mut ${ }^{+}$: methanol utilization phenotype; wildtype; Mut ${ }^{\text {: }}$ : methanol utilization slow phenotype; $\mathrm{OD}_{600}$ : optical density at $600 \mathrm{~nm}$ [AU]; PID: proportional-integrative-derivative controller; $\mathrm{qCO}_{2}$ : specific carbon dioxide production rate $\left[\mathrm{mmol} \cdot \mathrm{g}^{-1} \cdot \mathrm{h}^{-1}\right] ; \mathrm{qCO}_{2}$ : derivative of $\mathrm{qCO}_{2} ; \mathrm{q}_{\mathrm{p}}$ : specific productivity $\left[U \cdot g^{-1} \cdot h^{-1}\right] ; q_{s}$ adapt: specific substrate uptake rate during adaptation $\left[\mathrm{mmol} \cdot \mathrm{g}^{-1} \cdot \mathrm{h}^{-1}\right.$; $\mathrm{q}_{\mathrm{s}}$ max: maximum specific substrate uptake rate $\left[\mathrm{mmol} \cdot \mathrm{g}^{-1} \cdot \mathrm{h}^{-1}\right]$; $\mathrm{q}_{\mathrm{s}}$ : specific substrate uptake rate $\left[\mathrm{mmol} \cdot \mathrm{g}^{-1} \cdot \mathrm{h}^{-1}\right]$; rpm: rounds per minute; $\mathrm{RQ}$ : respiratory quotient; $\mathrm{V} v \mathrm{~m}$ : volume gas flow per volume liquid per minute

\section{Acknowledgements}

The authors are very grateful to Prof. Anton Glieder and his workgroup for providing all $P$. pastoris $\mathrm{Mut}^{\mathrm{S}}$ strains expressing the enzyme horseradish peroxidase. Additionally, the authors express their gratitude to Josef Schulze, who supported the experimental work in the lab.

\section{Authors' contributions}

CD designed and performed the majority of the experiments, analyzed the data and drafted the manuscript. OS designed and performed some experiments and finalized the manuscript. $\mathrm{CH}$ conceived the study and supervised research. All authors read and approved the final manuscript.

\section{Competing interests}

The authors declare that they have no competing interests.

Received: 9 August 2011 Accepted: 27 October 2011

Published: 27 October 2011

\section{References}

1. d'Anjou MC, Daugulis AJ: A rational approach to improving productivity in recombinant Pichia pastoris fermentation. Biotechnology and bioengineering 2001, 72:1-11.

2. Curvers S, Linnemann J, Klauser T, Wandrey C, Takors R: Recombinant protein production with Pichia pastoris in continuous fermentation kinetic analysis of growth and product formation. Engineering in Life Sciences 2002, 2:229-235.

3. Ren H, Yuan J: Model-based specific growth rate control for Pichia pastoris to improve recombinant protein production. Journal of Chemical Technology and Biotechnology 2005, 80:1268-1272.

4. Ren HT, Yuan JQ, Bellgardt KH: Macrokinetic model for methylotrophic Pichia pastoris based on stoichiometric balance. Journal of Biotechnology 2003, 106:53-68.

5. Invitrogen: Pichia Fermentation Process Guidelines. 2002

6. Jahic M, Rotticci-Mulder JC, Martinelle M, Hult K, Enfors SO: Modeling of growth and energy metabolism of Pichia pastoris producing a fusion protein. Bioprocess and Biosystems Engineering 2002, 24:385-393.

7. Trinh LB, Phue JN, Shiloach J: Effect of methanol feeding strategies on production and yield of recombinant mouse endostatin from Pichia pastoris. Biotechnology and Bioengineering 2003, 82:438-444

8. Z Zhang W, Bevins MA, Plantz BA, Smith LA, Meagher MM: Modeling Pichia pastoris growth on methanol and optimizing the production of a recombinant protein, the heavy-chain fragment $C$ of botulinum neurotoxin, serotype A. Biotechnology and Bioengineering 2000, 70:1-8.

9. Zhang W, Sinha J, Smith LA, Inan M, Meagher MM: Maximization of Production of Secreted Recombinant Proteins in Pichia pastoris FedBatch Fermentation. Biotechnology Progress 2005, 21:386-393.

10. Plantz BA, Sinha J, Villarete L, Nickerson KW, Schlegel VL: Pichia pastoris fermentation optimization: energy state and testing a growth-associated model. Applied Microbiology and Biotechnology 2006, 72:297-305.

11. Potgieter TI, Kersey SD, Mallem MR, Nylen AC, d'Anjou M: Antibody expression kinetics in glycoengineered Pichia pastoris. Biotechnology and Bioengineering 2010, 106:918-927.

12. Kobayashi K, Kuwae $S$, Ohya T, Ohda T, Ohyama M, Tomomitsu K: High level secretion of recombinant human serum albumin by fed-batch fermentation of the methylotrophic yeast, Pichia pastoris, based on optimal methanol feeding strategy. Journal of Bioscience and Bioengineering 2000, 90:280-288.

13. Jacobs $P$, Inan $M$, Festjens $N$, Haustraete J, Van Hecke A, Meagher $M$, Contreras R, Callewaert N: Fed-batch fermentation of GM-CSF-producing glycoengineered Pichia pastoris under controlled specific growth rate. Microbial Cell Factories 2010, 9:93.

14. Sinha J, Plantz BA, Zhang W, Gouthro M, Schlegel V, Liu C-P, Meagher MM: Improved production of recombinant ovine interferon-t by Mut+ strain of Pichia pastoris using an optimized methanol feed profile. Biotechnology Progress 2003, 19:794-802.

15. Khatri NK, Hoffmann F: Oxygen-limited control of methanol uptake for improved production of a single-chain antibody fragment with 
recombinant Pichia pastoris. Applied Microbiology and Biotechnology 2006, 72:492-498.

16. Khatri NK, Hoffmann F: Impact of methanol concentration on secreted protein production in oxygen-limited cultures of recombinant Pichia pastoris. Biotechnology and Bioengineering 2006, 93:871-879.

17. Cunha AE, Clemente JJ, Gomes R, Pinto F, Thomaz M, Miranda S, Pinto R, Moosmayer D, Donner P, Carrondo MJT: Methanol induction optimization for scFv antibody fragment production in Pichia pastoris. Biotechnology and bioengineering 2004, 86:458-467.

18. Dietzsch C, Spadiut O, Herwig C: A dynamic method based on the specific substrate uptake rate to set up a feeding strategy for Pichia pastoris. Microbial Cell Factories 2011, 10:14.

19. Hartner FS, Ruth C, Langenegger D, Johnson SN, Hyka P, Lin-Cereghino GP, Lin-Cereghino J, Kovar K, Cregg JM, Glieder A: Promoter library designed for fine-tuned gene expression in Pichia pastoris. Nucleic Acids Research 2008, 36:e76/71-e76/15.

20. Spadiut $\mathrm{O}$, Olsson $\mathrm{L}$, Brumer $\mathrm{H}$ : A comparative summary of expression systems for the recombinant production of galactose oxidase. Microb Cell Fact 2010, 9:68.

21. Cregg JM: Pichia Protocols, Second Edition. In Methods Mol Biol. Edited by: Cregg JM. Totowa, NJ, U. S.; 2007:268.

22. Herwig $C$, von Stockar U: A small metabolic flux model to identify transient metabolic regulations in Saccharomyces cerevisiae. Bioprocess and Biosystems Engineering 2002, 24:395-403.

23. Diderich JA, Schepper M, van Hoek P, Luttik MA, van Dijken JP, Pronk JT, Klaassen P, Boelens HF, de Mattos MJ, van Dam K, Kruckeberg AL: Glucose uptake kinetics and transcription of HXT genes in chemostat cultures of Saccharomyces cerevisiae. The Journal of biological chemistry 1999, 274:15350-15359.

24. Rizzi M, Theobald U, Querfurth E, Rohrhirsch T, Baltes M, Reuss M: In vivo investigations of glucose transport in Saccharomyces cerevisiae. Biotechnology and Bioengineering 1996, 49:316-327.

25. Duboc $P$, Von Stockar U, Villadsen J: Simple generic model for dynamic experiments with Saccharomyces cerevisiae in continuous culture: decoupling between anabolism and catabolism. Biotechnology and Bioengineering 1998, 60:180-189.

26. Duboc $P$, Cascao-Pereira LG, von Stockar U: Identification and control of oxidative metabolism in Saccharomyces cerevisiae during transient growth using calorimetric measurements. Biotechnology and Bioengineering 1998, 57:610-619.

doi:10.1186/1475-2859-10-85

Cite this article as: Dietzsch et al: A fast approach to determine a fed batch feeding profile for recombinant Pichia pastoris strains. Microbial Cell Factories 2011 10:85.

\section{Submit your next manuscript to BioMed Central and take full advantage of:}

- Convenient online submission

- Thorough peer review

- No space constraints or color figure charges

- Immediate publication on acceptance

- Inclusion in PubMed, CAS, Scopus and Google Scholar

- Research which is freely available for redistribution

Submit your manuscript at www.biomedcentral.com/submit
Biomed Central 